\title{
Nutcracker syndrome in pregnancy: a worrying presentation of a benign condition
}

\author{
MB Motha, TS Palihawadana, TD Dias, PS Wijesinghe
}

Ceylon Medical Journal 2017; 62: 238-39

DOI: http://doi.org/10.4038/cmj.v62i4.8574

\section{Introduction}

Macroscopic haematuria in pregnancy is rare. Underlying aetiologies include urinary tract infections, calculi, tumours and trauma as well as pregnancy specific causes such as placental percreta. It is a worrying symptom, especially when there is persistent gross haematuria.

Nutcracker syndrome is a very rare cause of haematuria that results from mechanical obstruction of the left renal vein between the descending aorta and the superior mesenteric artery. The compression leads to development of an extensive collateral venous drainage system involving the left gonadal capsular, suprarenal, lumbar, azygous and peri-ureteral veins. The appearance resembles a nut caught between the jaws of a nutcracker and thus the name nutcracker syndrome. It was first decribed by the anatomist Grant in 1937 [1]. Haematuria results when the thin walled septum separating the varicosities from the urinary collecting system ruptures. This may occur in the presence of a reduced angle between the aorta and the superior mesenteric artery or due to increase in aortic diameter that occurs during pregnancy. The most common presentation is intermittent microscopic haematuria, while gross hematuria and left flank pain secondary to the passage of ureteral blood clots is rare. Symptoms of pelvic venous congestion (chronic pelvic pain, dyspareunia and dysmenorrhea) may also occur in females $[2,3]$.

We report a pregnant woman who presented with persistent gross haematuria secondary to nutcracker syndrome. This describes a severe form of the condition, which has not been described in literature before.

\section{Case history}

A 30 year old housewife in her second pregnancy was transferred from a Base Hospital at 31 weeks of gestation for investigation of macroscopic haematuria of two weeks duration. Her first pregnancy had been uncomplicated. She did not have a history of bleeding from other sites or family history of bleeding diathesis. On examination she was pale, blood pressure was $100 / 70 \mathrm{mmHg}$. There was no ankle oedema. Abdominal examination did not reveal loin tenderness or palpable masses. Examination of the respiratory, cardiovascular and nervous systems were unremarkable. She had received five packs of red blood cells in the preceding two weeks. The lowest haemoglobin level recorded was $5.1 \mathrm{~g} / \mathrm{dl}$.

Urine full report showed field full of red blood cells with no evidence of proteinuria, pus cells, red blood cell casts or dysmorphic cells. Serum creatinine was $38 \mu \mathrm{mol} / 1$. Haemoglobin was $8.5 \mathrm{~g} / \mathrm{dl}$ on admission and platelet count was $390 \times 109 / \mathrm{mm} 3$. The clotting profile which included bleeding time, clotting time, and prothrombin time were normal. Serum antinuclear antibodies were absent. Ultrasound scan revealed normal kidneys. Cystoscopic evaluation showed a healthy urothelium with no obvious source of bleeding. Foetal assessment, which included an ultrasound, was normal and the placenta was located in the fundal region.

A clinical diagnosis of nutcracker syndrome was made in the absence of an alternative cause. A conservative management plan was adopted. She was monitored as an outpatient with weekly haemoglobin counts and foetal assessments. She required further 3 units of red blood cell packs over the next six weeks. She delivered a healthy baby weighing $2.9 \mathrm{~kg}$ at 37 weeks of gestation following spontaneous onset of labour. She was offered a computerised tomographic angiography on the first postpartum day which showed compression of the left renal vein anterior to the descending aorta confirming

1Department of Obstetrics and Gynaecology, University of Kelaniya.

Correspondence: MBM, e-mail: <cmotha6@gmail.com>. Received 06 November 2015 and revised version accepted 12 September 2017 


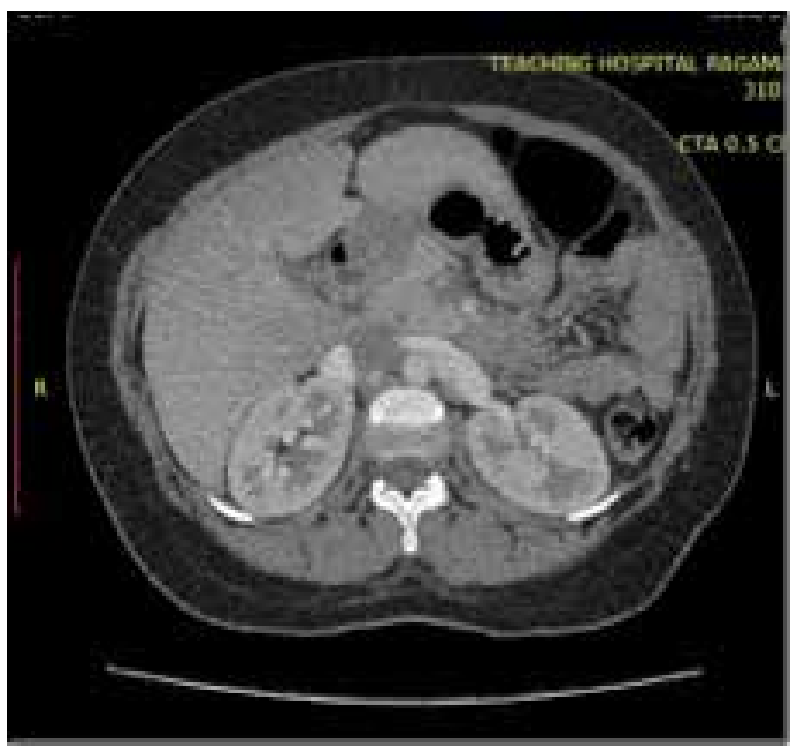

Figure 1. CT angiogram of the abdomen showing stenosis of the left renal vein anterior to the aorta

nutcracker syndrome. (Figure 1). Haematuria resolved by the 4th postpartum day. She was reviewed at 6 weeks postpartum and had not experienced further episodes of haematuria.

\section{Discussion}

Pregnancy predisposes to nutcracker syndrome though there are only few cases reported in the literature. Previous reports include a woman with nutcracker syndrome in the third trimester curtailed by elective delivery and a woman who had severe vulval varicosities during pregnancy $[4,5]$. Previous case reports during pregnancy have not described this degree of haematuria.

The definitive diagnostic test is retrograde venography which allows both determination of the renocaval pressure gradient and contrast mapping of the dilated gonadal vein and the perihilar, periureteral, and pelvic collateral network. Other radiographic features include reduced angle between the aorta and superior mesenteric and left renal vein stenosis, as depicted in our patient. Retrograde venography was not available at our center thus a CT angiography was performed to illustrate the radiographic features.
Though various surgical procedures such as left renal vein transposition to the more inferior inferior vena cava, external venous stent placement, left renal vein bypass surgery, renal autotransplantation to the iliac fossa, and left nephrectomy have been described in treating the nonpregnant population, the reversible nature of the aetiology during pregnancy seldom necessitate such interventions during pregnancy. The absence of any abnormality on renal and haematological investigations as well as normal fetal wellbeing enabled a conservative approach in managing the pregnancy in this patient. A strong clinical suspicion will enable the clinician to make the diagnosis which can be confirmed by magnetic resonance imaging even during pregnancy.

\section{References}

1. Grant JCB. A method of anatomy: descriptive and deductive. 3rd ed. Baltimore: Williams \& Wilkins, 1944.

2. Scultetus AH, Villavicencio JL, Gillespie DL. The nutcracker syndrome: its role in the pelvic venous disorders. J Vasc Surg 2001;34(5):812-819

3. Lamba R, Tanner DT, Sekhon S, McGahan JP, Corwin MT, Lall CG. Multidetector CT of Vascular Compression Syndromes in the Abdomen and Pelvis Gastrointestinal Imaging. Radiographics 2014; 34(1): 93-115

4. Itoh S, Yoshida K, Nakamura Y, Mitsuhashi N. Aggravation of the Nutcracker syndrome during pregnancy. Obstet Gynecol 1997; 90: 661-3

5. Singh R, Griffiths A, Trivedi A. Nutcracker syndrome in pregnancy: A tough nut to crack? Aust N Z J Obstet Gynaecol 2008; 48: 119-123 